\title{
Once-weekly hemodialysis combined with low-protein and low-salt dietary treatment as a favorable therapeutic modality for selected patients with end-stage renal failure: a prospective observational study in Japanese patients
}

Toshiyuki Nakao ${ }^{1,2,3^{*}}$, Yoshie Kanazawa ${ }^{1,2}$ and Toshimasa Takahashi ${ }^{1,3}$

\begin{abstract}
Background: For patients with end-stage renal failure (ESFR), thrice-weekly hemodialysis is a standard care. Once-weekly hemodialysis combined with low-protein and low-salt dietary treatment (OWHD-DT) have been rarely studied. Therefore, here, we describe our experience on OWHD-DT, and assess its long-term effectiveness.

Methods: We instituted OWHD-DT therapy in 112 highly motivated patients with creatinine clearance below $5.0 \mathrm{~mL} / \mathrm{min}$. They received once-weekly hemodialysis on a diet of $0.6 \mathrm{~g} / \mathrm{kg} /$ day of protein adjusted for sufficient energy intake, and less than $6 \mathrm{~g} /$ day of salt intake. Serial changes in their clinical, biochemical and nutritional parameters were prospectively observed, and the weekly time spent for hospital visits as well as their monthly medical expenses were compared with 30 age, sex- and disease-matched thrice-weekly hemodialysis patients.

Results: The duration of successfully continued OWHD-DT therapy was more than 4 years in $11.6 \%$ of patients, 3 years in $16.1 \%, 2$ years in $24.1 \%$ and 1 year in $51.8 \%$. Time required per week for hospital attendance was $66.7 \%$ shorter and monthly medical expenses were $50.5 \%$ lower in the OWHD-DT group than in the thrice-weekly hemodialysis group (both $p<0.001$ ). Patient survival rates in the OWHD-DT group were better than those in the Japan Registry $(p<0.001)$. Serum urea nitrogen significantly decreased; hemoglobin significantly increased; and albumin and body mass index were not significantly different from baseline values. In the OWHD-DT patients, serum albumin at 1 and 2 years after initiation of therapy was significantly higher compared with prevalent thrice-weekly hemodialysis patients. Furthermore, residual urine output was significantly higher in the OWHD-DT patients than in those receiving thrice-weekly hemodialysis $(p<0.05)$. Interdialytic weight gain over the course of the entire week between treatments in patients on OWHD-DT were $0.9 \pm 1.0,2.0 \pm 1.3,1.9 \pm 1.2,1.9 \pm 1.5$ and $1.8 \pm 1.0 \mathrm{~kg}$ at $1,6,12,18$ and 24 months, respectively, though the weekly weight gain for thrice-weekly hemodialysis group (summed over all 3 treatments) was $8.6 \pm 0.63 \mathrm{~kg}, p<0.001$.

(Continued on next page)
\end{abstract}

\footnotetext{
* Correspondence: t-nakao@tokyo-med.ac.jp

'Department of Clinical Research, Organization for Kidney and Metabolic

Disease Treatment, 1-32-1, Okusawa, Setagaya ward, Tokyo 158-0083, Japan

${ }^{2}$ Department of Human Nutrition, Tokyo Kaseigakuin University, 22,

sanbanchou, Chiyoda ward, Tokyo 102-8341, Japan

Full list of author information is available at the end of the article
}

(c) The Author(s). 2018 Open Access This article is distributed under the terms of the Creative Commons Attribution 4.0 International License (http://creativecommons.org/licenses/by/4.0/), which permits unrestricted use, distribution, and reproduction in any medium, provided you give appropriate credit to the original author(s) and the source, provide a link to the Creative Commons license, and indicate if changes were made. The Creative Commons Public Domain Dedication waiver (http://creativecommons.org/publicdomain/zero/1.0/) applies to the data made available in this article, unless otherwise stated. 
(Continued from previous page)

Conclusions: OWHD-DT may be a favorable therapeutic modality for selected highly motivated patients with ESRF. However, this treatment cannot be seen as a general maintenance strategy.

Trial registration: UMIN000027555, May 30, 2017 (retrospectively registered).

Keywords: Once-weekly hemodialysis, Infrequent dialysis, Low protein diet, End-stage renal failure, Dialysis adequacy

\section{Background}

Hemodialysis (HD) three times per week is the conventional standard method to treat patients with end-stage renal failure (ESRF) in whom uremia can no longer be managed conservatively. Argument on dialysis adequacy has always been based on thrice-weekly HD for the last 30 years, [1-3], and less frequent dialysis has rarely been the subject of study. Recently, however, twice-weekly HD has been proposed as a new paradigm for initiation of HD in ESRF patients with significant residual kidney function [4-6]. Clinical guidelines approve this approach in certain settings $[7,8]$. Irrespective of dialysis frequency, standard recommended dietary protein intake is $1.0-1.2 \mathrm{~g} / \mathrm{kg} /$ day $[9,10]$, which is higher than that recommended for healthy populations [11].

A low-protein diet has long been used for reducing the retention of nitrogenous toxic metabolites in chronic renal failure [12-15]. Dietary treatment (DT) consisting of low-protein and low-salt intake can forestall the development of uremic symptoms, and has played a central role in the conservative management of ESRF for decades [16-18]. Some patients show good adherence to DT, and thus can successfully postpone the initiation of dialysis [19-21]. Because these patients have put significant effort into their own health, the sudden transition from conservative therapy with a low-protein diet to conventional thrice-weekly HD with a usual-protein diet (C-HD) can be psychologically unacceptable, despite the deterioration of their renal function to critical levels. In these cases, a staged transition by which HD is given at a low frequency might be considered.

One session of HD for ESRF patients can remove excess body fluids and decrease accumulated metabolites to near normal levels. However, during the interval between HD sessions, fluids and toxic metabolites accumulate in the body through the ingestion of foods and drinks. Under these circumstances, DT with a low-protein and low-salt diet can slow the accumulation of fluids and toxic metabolites, thus increasing the necessary intervals between HD. It seems reasonable, therefore, that a combined treatment of infrequent HD and DT would be worth trying as an alternative to $\mathrm{C}$-HD.

To date, however, only a few studies on the combined treatment of infrequent HD and DT, have been reported [22-27]. Therefore, in this study, we describe our experiences with a combined therapy consisting of once-weekly hemodialysis and DT with a low-protein and a low-salt intake (OWHD-DT). We then assessed the long-term effectiveness of this alternative therapy.

\section{Methods \\ Patients}

Between 1992 and 2014, 112 consecutive patients treated with OWHD-DT at Tokyo Medical University Hospital and Bousei Shinjuku-minamiguchi Clinic, and followed until the end of 2016, were enrolled in this study.

Criteria for patient selection was as follows: 1) creatinine clearance below $5.0 \mathrm{~mL} / \mathrm{min}$ or serum creatinine over $8.0 \mathrm{mg} / \mathrm{dL}, 2)$ clinical emergence of uremic gastrointestinal symptoms or other uremic symptoms on conservative treatment, and 3) patient willingness and high motivation to choose the therapeutic modality, OWHD-DT, with informed consents. Patients who met all three criteria were instituted to OWHD-DT. They were changed to $\mathrm{C}-\mathrm{HD}$ if either they did not remain motivated to adhere to the required $\mathrm{DT}$, or if their residual urine output decreased to $\leqq 500 \mathrm{~mL} /$ day with concomitant concern for the emergence of uremic symptoms necessitating an increased rate of dialysis.

On October, 2013, 30 outpatient on C-HD at Bousei Shinjuku-minamiguchi Clinic were recruited, in order to compare their overall monthly medical expenses, the weekly time required for medical treatment including both dialysis and hospital attendance, daily urine output, the weekly interdialytic weight gain (IDW) and the dietary salt and protein intake, with the patients on OWHD-DT. In comparison of IDW, the average over 4 weeks of IDW was examined. The weekly IDW was the sum of weight gains for all 3 treatments per week for patients on $\mathrm{C}-\mathrm{HD}$, and was the weight gain for the entire week between once-weekly treatments for patients on OWHD-DT. Salt intake was calculated as (IDW $\times$ serum sodium concentration + urinary sodium excretion)/17, and protein intake was calculated from patients' diet dairies.

Written informed consent was obtained from all patients, and the studies were conducted in accordance with the principles set out in the Declaration of Helsinki regarding clinical trials with human subjects. The study was approved by the ethics committee of Tokyo Medical University. 


\section{Hemodialysis}

HD was conducted every 7 days, using high-flux polysulfone membrane dialyzers, at a blood flow rate of 200-250 $\mathrm{mL} / \mathrm{min}$ and a dialysate flow rate of $500 \mathrm{~mL} / \mathrm{min}$. The length of each dialysis session was 3.5 to $5 \mathrm{~h}$. The fluid removal rate varied according to the volume accumulated in the patient, and was kept constant from the beginning to the end of the HD session.

\section{Dietary treatment}

The patients were advised to follow a low-protein, low-salt diet with sufficient energy intake and received nutritional counselling by a renal dietician once or twice a month. The prescribed diet consisted of daily intake of $0.6 \mathrm{~g} / \mathrm{kg}$ standardized body weight of protein, with approximately $65 \%$ of the dietary protein of high biological value (i.e., from animal sources). Prescribed salt intake was less than $6 \mathrm{~g} /$ day. A $6 \mathrm{~g}$ portion of salt contains $2.4 \mathrm{~g}$ of sodium. Energy intake consisting primarily of carbohydrates and fats was individually prescribed for each patient, in equilibrium with estimated energy expenditure as determined by their sex, age and physical activity. The average prescribed daily energy intake was $32 \pm 2 \mathrm{kcal} / \mathrm{kg}$.

A skilled dietitian trained the patients to follow the diet, including how to use specially manufactured protein-reduced energy-equivalent rice, noodles, and bread products to make up for energy lost through decreased protein intake. Protein-reduced rice was manufactured by treating ordinary rice by enzymes that degrade proteins to the level of $1 / 25$ th, followed steaming, and packing in $200 \mathrm{~g}$ plastic container. Protein-reduced bread and pasta were prepared from corn starch, gum, yeast and sugar. The patients on OWHD-DT purchased those specifically manufactured foods by themselves. Patients not on the protocol did not obtain similar diets. If a patient not on the protocol wanted to consume this diet, he/her can purchase the foods through http:// www.healthynetwork.co.jp

Fluid intake was interviewed by nurses at the time of every dialysis treatment. Strict restriction of water intake was not instructed; instead salt restriction was strictly instructed and repeatedly consulted, since intake of salt directly results in ingestion of water in ESRF patients. A typical diet for a single day for an OWHD-DT patient is shown in Table 1. Adherence to the low-protein/low-salt diet was evaluated monthly by a skilled dietitian, YK, based on the patients' diet diary, interview with the patients and 24-h urine collection.

\section{Laboratory measurements}

Blood samples and blood pressure were obtained at the start of HD. 24-h urine collections were examined monthly. Serum albumin was measured by the BCG
Table 1 A typical diet for a single day for an OWHD-DT patient

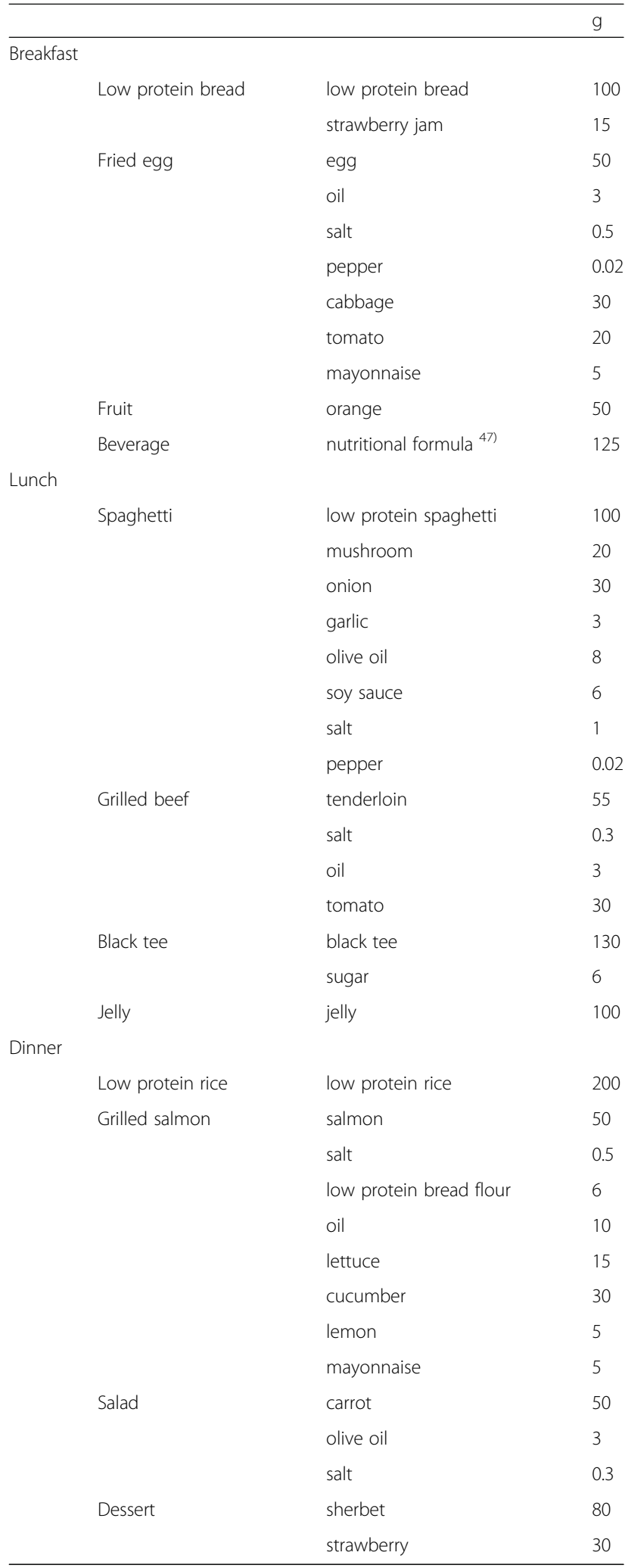

Total energy $2067 \mathrm{kcal}$, protein $34.8 \mathrm{~g}$, fat $64 \mathrm{~g}$, carbohydrate $344.1 \mathrm{~g}$ potassium $1290 \mathrm{mg}$, phosphorus $540 \mathrm{mg}$, salt $5.5 \mathrm{~g}$, amino acid score 100 $O W H D-D T$, Once-weekly hemodialysis combined with dietary treatment 
method. A chest radiograph was obtained just after HD, and cardiothoracic ratio was measured. Body mass index (BMI) was calculated as body weight $(\mathrm{kg})$ divided by height squared $\left(\mathrm{m}^{2}\right)$. The calculation of BMI was based on body weight just after HD.

\section{Statistical analyses}

Data are expressed as means \pm SD. Testing for statistical significance was conducted using the t-test for parametric variables and the Mann-Whitney $\mathrm{U}$ test for nonparametric variables. A $p$-value of $<0.05$ was considered to be statistically significant. A Kaplan-Meier curve was drawn to present the survival of the patients. SPSS statistical software (version 21; IBM Corporation, Chicago, IL) was used for all calculations.

\section{Results}

\section{Patient characteristics}

Median age of the patients was 63 (interquartile range: 53-69) years old at the start of OWHD-DT. Diseases leading to renal failure, vascular access and prescribed medications at the initiation of OWHD-DT were shown in Table 2. A total of $97.3 \%$ of the patients began OWHD-DT at an outpatient clinic and the

Table 2 Patient characteristics at the initiation of OWHD-DT

\begin{tabular}{ll}
\hline Characteristic & Total $n=112$ \\
\hline Age (yr) & $63(53-69)$ \\
Men, $n$ (\%) & $80(71.4)$ \\
Diseases, $n$ (\%) & \\
Chronic glomerulonephritis & $38(33.9)$ \\
Diabetic nephropathy & $38(33.9)$ \\
Nephroscrelosis & $22(19.6)$ \\
Polycystic kidney & $9(8.0)$ \\
Urological disease & $3(2.7)$ \\
Chronic interstitial nephritis & $2(1.8)$ \\
Pretreatment, $n$ (\%) & \\
Conservative therapy & $97(86.6)$ \\
Twice-weekly hemodialysis & $14(12.5)$ \\
Thrice-weekly hemodialysis & $1(0.9)$ \\
Vascular access, A-V fistula, $n$ (\%) & $112(100)$ \\
Medications, $n$ (\%) & \\
Duretics & $107(95.5)$ \\
Erythropoesis stimulating agent & $111(99.1)$ \\
Antihypertensives & $87(77.7)$ \\
Phosphate binders & $84(75.0)$ \\
Activated vitamin D & $89(79.5)$ \\
Alkalizing agents & $62(55.3)$ \\
\hline OWHD-DT, Once-weekly hemodialysis combined with dietary treatment & $15(13.3)$ \\
\hline
\end{tabular}

OWHD-DT, Once-weekly hemodialysis combined with dietary treatment other $2.7 \%$ on admission to the hospital. Creatinine clearance of the studied patients at the initiation of HD was $3.8 \pm 0.8 \mathrm{~mL} / \mathrm{min}$, and urea clearance $2.3 \pm$ $0.7 \mathrm{ml} / \mathrm{min}$. Mean single pool $\mathrm{Kt} / \mathrm{V}(\mathrm{spKt} / \mathrm{V})$ per a HD session was $1.34 \pm 0.13$.

\section{Outcomes}

The patients on OWHD-DT were changed to twice-weekly or thrice-weekly HD, when they became unable to adhere the DT or when their residual urine output decreased to $\leqq 500 \mathrm{~mL} /$ day with a concomitant fear of the emergence of uremic symptoms. Continuation and outcomes are shown in Table 3, and the longest was 11.5 years. 38 out of 112 (33.9\%) patients quit the protocol because they did not remain motivated to adhere to the diet. Especially for the 26 patients who quit the protocol within 6 months, the most reason (96.2\%) of discontinuation was poor adherence to the diet, mainly because of palatability for the diet and frequent eating out. On the other hand, in all 39 patients on OWHD-DT over 18 months or longer, adherence to the diet was excellent, and their reasons of discontinuing the protocol were reduction of residual urine outputs.

Serial changes in biochemical and clinical parameters after beginning of OWHD-DT are shown in Table 4. Interdialytic weight gain (IDW) were $0.9 \pm 1.0,2.0 \pm 1.3$, $1.9 \pm 1.2,1.9 \pm 1.5$ and $1.8 \pm 1.0 \mathrm{~kg}$ at the first month, 6 , 12, 18 and 24 months, respectively (Fig. 1). The values of IDW are for the entire week between treatments. The IDW value of each patient is the mean of 4 values for the entire week between treatments at follow-up time points. On the other hand, the weekly IDW for $\mathrm{CH}$-D group (summed over all 3 treatments) was $8.6 \pm 0.63 \mathrm{~kg}$, $p<0.001$.

Table 3 Continuation and outcomes

\begin{tabular}{lll}
\hline Time (months) & $\begin{array}{l}\text { Number of patients on } \\
\text { the OWHD-DT } n,(\%)\end{array}$ & \\
\hline 0 & $112(100)$ & 26 transferred to C-HD \\
6 & $86(76.7)$ & 27 transferred to C-HD, 1 died \\
12 & $58(51.8)$ & 18 transferred to C-HD, 1 \\
18 & $39(34.8)$ & transplanted \\
24 & $27(24.1)$ & 11 transferred to C-HD, 1 died \\
30 & $20(17.8)$ & 2 transferred to C-HD \\
36 & $18(16.1)$ & 3 transferred to C-HD \\
42 & $15(13.4)$ & 2 transferred to C-HD \\
48 & $13(11.6)$ & 2 transferred to C-HD \\
54 & $11(9.8)$ & 1 transferred to C-HD \\
\hline 60 & $10(8.9)$ &
\end{tabular}

OWHD-DT, Once-weekly hemodialysis combined with dietary treatment; $C-H D$, Conventional twice- or thrice- weekly dialysis 
Table 4 Biochemical and clinical parameters in patients on OWHD-DT at follow-up time points during 24 months of the study

\begin{tabular}{|c|c|c|c|c|c|}
\hline Duration (months) & $O M$ & $6 \mathrm{M}$ & $12 \mathrm{M}$ & $18 \mathrm{M}$ & $24 \mathrm{M}$ \\
\hline Number of the patients & 112 & 86 & 58 & 39 & 27 \\
\hline Urea nitrogen (mg/dl) & $98.5 \pm 30.0$ & $83.9 \pm 17.0 \S$ & $85.4 \pm 23.2 \#$ & $85.7 \pm 22.1 \#$ & $77.2 \pm 15.8+$ \\
\hline Creatinine (mg/dl) & $11.7 \pm 4.0$ & $12.2 \pm 4.1$ & $12.5 \pm 3.8 \#$ & $12.8 \pm 4.3 \dagger$ & $12.6 \pm 4.4 \#$ \\
\hline$\beta 2$ microglobulin (mg/L) & $19.5 \pm 5.6$ & $23.1 \pm 7.7 \dagger$ & $23.3 \pm 7.2+$ & $23.5 \pm 7.3$ & $24.4 \pm 7.5$ \\
\hline Sodium (mEq/l) & $136.6 \pm 5.6$ & $138.6 \pm 3.8 \dagger$ & $138.5 \pm 3.6+$ & $138.9 \pm 4.2 \dagger$ & $139.2 \pm 4.6$ \\
\hline Potasium (mEq/l & $4.3 \pm 0.8$ & $4.6 \pm 0.8 \#$ & $4.7 \pm 0.9 \S$ & $4.6 \pm 0.7 \#$ & $4.8 \pm 0.8 \dagger$ \\
\hline Calsium (mg/dl) & $8.0 \pm 1.2$ & $8.9 \pm 1.2 \S$ & $8.9 \pm 1.2+$ & $8.5 \pm 0.4 \S$ & $8.7 \pm 0.4 \#$ \\
\hline Posphate (mg/dl) & $6.4 \pm 1.9$ & $5.8 \pm 1.7$ & $6.0 \pm 1.5$ & $5.7 \pm 1.3$ & $5.8 \pm 1.4$ \\
\hline Bicarbonate (mEq/l) & $18.7 \pm 4.7$ & $21.8 \pm 2.3$ & $22.3 \pm 3.3$ & $21.9 \pm 1.9$ & $22.0 \pm 2.9$ \\
\hline Hemoglobin (g/dl) & $8.7 \pm 1.2$ & $10.3 \pm 1.5 \S$ & $10.0 \pm 1.6 \#$ & $10.6 \pm 0.8+$ & $10.6 \pm 1.2 \dagger$ \\
\hline Albumin (g/dl) & $3.9 \pm 0.5$ & $4.1 \pm 0.4$ & $4.1 \pm 0.4$ & $4.0 \pm 0.3$ & $4.0 \pm 0.3$ \\
\hline Transferin (mg/dl) & $204.1 \pm 45.4$ & $211.8 \pm 45.6$ & $214.1 \pm 37.5$ & $212.6 \pm 42.7$ & $209.3 \pm 34.7$ \\
\hline BMI (kg/m2) & $20.9 \pm 2.6$ & $21.1 \pm 2.6$ & $21.1 \pm 2.9$ & $20.6 \pm 2.7$ & $20.7 \pm 2.6$ \\
\hline iPTH (pg/ml) & $263.1 \pm 204.4$ & $151.1 \pm 141.4 \S$ & $129.9 \pm 79.5 \#$ & $132.5 \pm 68.7 \#$ & $142.1 \pm 146.4 \#$ \\
\hline CRP (mg/L) & $1.27 \pm 1.18$ & $1.11 \pm 0.98$ & $1.52 \pm 1.63$ & $1.45 \pm 1.63$ & $1.05 \pm 1.21$ \\
\hline Systolic blood pressure $(\mathrm{mmHg})$ & $154.0 \pm 19.9$ & $156.3 \pm 20.4$ & $153.7 \pm 16.9$ & $154.0 \pm 20.1$ & $150.5 \pm 17.6$ \\
\hline Diastolic blood pressure $(\mathrm{mmHg})$ & $81.8 \pm 12.2$ & $84.1 \pm 12.4$ & $83.3 \pm 10.8$ & $83.1 \pm 11.7$ & $81.8 \pm 12.1$ \\
\hline CTR (\%) & $49.6 \pm 5.9$ & $49.1 \pm 4.4$ & $49.5 \pm 5.3$ & $48.5 \pm 4.8$ & $48.3 \pm 3.7$ \\
\hline
\end{tabular}

OWHD-DT, Once-weekly hemodialysis combined with dietary treatment; BMI, Body mass index; iPTH, Intact parathyroid hormone; CRP, C-reactive protein; $C T R$, cardiothrasic ratio

$\S p<0.001 ; \# p<0.01 ;+p<0.05$ vs. baseline

Actual daily salt intake was $6.3 \pm 1.5 \mathrm{~g}$ in the patients on OWHD-DT at the first month vs. $13.7 \pm 2.7 \mathrm{~g}$ in C-HD group, $\mathrm{p}<0.001$. Actual daily protein intake was $0.65 \pm 0.06 \mathrm{~g} / \mathrm{kg}$ in the patients on OWHD-DT at the first month vs. $1.04 \pm 0.12 \mathrm{~g}$ for C-HD group, $p<0.001$.

Mean serum albumin concentrations in patients on OWHD-DT were $4.1 \pm 0.4 \mathrm{~g} / \mathrm{dL}$ at 12 months and $4.0 \pm$ $0.3 \mathrm{~g} / \mathrm{dL}$ at 24 months. These values were higher than the value of $3.6 \pm 0.6 \mathrm{~g} / \mathrm{dL}$ of patients enrolled in the

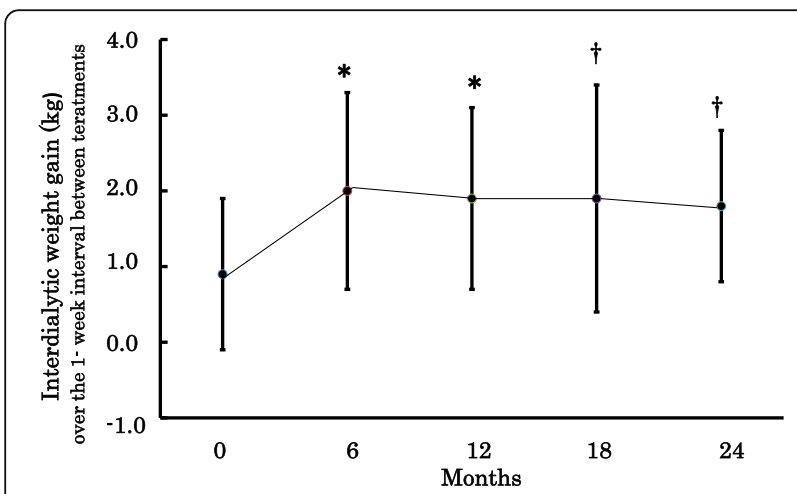

Fig. 1 Interdialytic weight gain (IDW) for the entire week between treatments in the patients who remained on once-weekly hemodialysis and diet therapy (OWHD-DT). The IDW value of each patient is the mean of 4 values for the entire week between treatments at follow-up time points. $* p<0.001,+p<0.05$ vs. baseline international Dialysis Outcomes and Practice Patterns Study (DOPPS) [28], (Fig. 2). The patients on OWHD-DT had significantly greater urine output than those on C-HD at 12 months after the initiation of HD $(1161.5 \pm 301.6 \mathrm{vs}$ $412.0 \pm 299.8 \mathrm{~mL} /$ day, $p<0.001$, Fig. 3 ), and mean clearance of creatinine and urea was $2.1 \pm 0.6$ vs $0.7 \pm 0.5 \mathrm{ml} /$ minute, $p<0.001$ ).

\section{Time required and cost for medical treatment}

We compared the time required for medical treatment including both dialysis and hospital attendance, which means the time per week for dialysis therapy plus the time for round-trip from home to hospital, between the

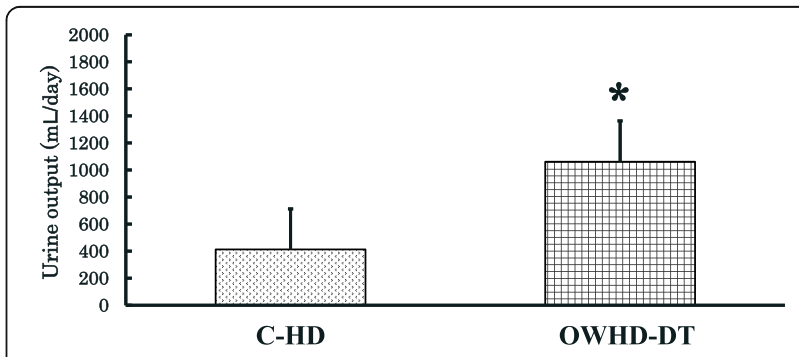

Fig. 3 Comparison of residual urine output at 12 months after initiation of hemodialysis between patients on conventional hemodialysis (C-HD) and those on once-weekly hemodialysis and diet therapy (OWHD-DT). $* p<0.001$ 


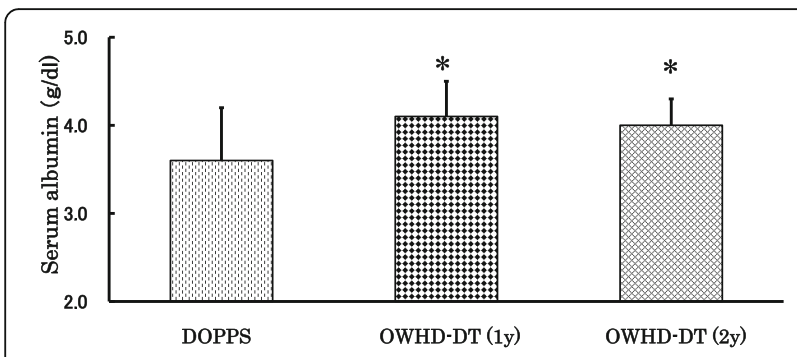

Fig. 2 Serum albumin concentrations at 1 year and 2 years in patients on once-weekly hemodialysis and diet therapy (OWHD-DT), compared with International Dialysis Outcomes and Practice Patterns Study (DOPPS) patients. $* p<0.001$

patients on OWHD-DT and the 30 prevalent patients on $\mathrm{C}-\mathrm{HD}$. The average time required for medical treatment was $5.9 \pm 0.8 \mathrm{~h}$ for the patients on OWHD-DT and $17.7 \pm 0.7 \mathrm{~h}$ for those on C-HD $(p<0.001)$. As expected from the once-weekly versus thrice-weekly HD, OWHD-DT patients required one third of the time for medical treatment compared with $\mathrm{C}-\mathrm{HD}$ patients (Fig. 4a).

We also compared the monthly costs of treatment between the patients on OWHD-DT and those on C-HD. The average monthly cost of treatment, including facility services, professional services, and outpatient pharmacy,

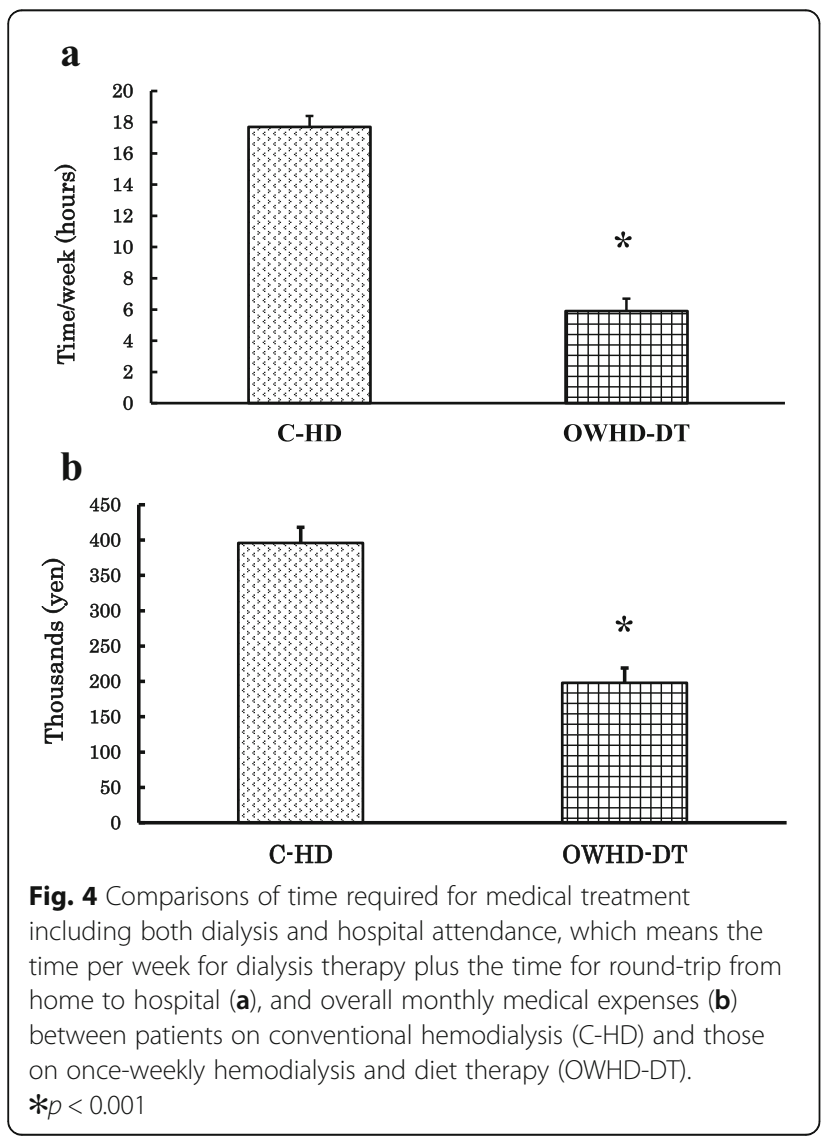

was $198.1 \pm 21.7$ thousand yen for those on OWHD-DT and $399.2 \pm 22.3$ thousand yen on controls on C-HD $(p<0.001)$. The medical expenses for patients undergoing OWHD-DT were about 50\% lower than those on C-HD (Fig. 4b).

\section{Patient survival}

Extended follow-up analysis of the patients showed survival rates of 92.4, 88.6, 81.4, 74.7, and $67.4 \%$ at $1,2,3$, 4 , and 5 years, respectively, including time after transition to twice-weekly or thrice-weekly HD. The survival rates of the patients on OWHD-DT were better than those patients in the Japan Registry which are 86.6, 79.4, $72.5,66.0$, and $59.4 \%$ at $1,2,3,4$, and 5 years respectively. The Japan Registry contains 36,711 patients who had newly started maintenance hemodialysis in 2007 [29] (Fig. 5).

\section{Discussion}

In this paper, we report the possibility that once-weekly dialysis can be successful if combined with strict low-protein and low-salt DT that can be well adhered to for patients with ESRF, whose renal function has diminished to the point that uremia cannot be controlled by the DT alone. OWHD-DT may be a safe and cost-effectiveness regimen that provides more HD-free time for selected patients. The main reasons for dropping out were loss of dietary adherence and/or reduction of residual renal function. We were unable to show any adverse effects of this treatment strategy, and the clinical outcomes were actually somewhat better than the overall outcomes of incident patients in Japan. The absence of adverse events may have been due to preferential selection of patients who had high motivation to adhere to the strategy and some residual renal function.

In spite of the fact that thrice-weekly HD became the standard method to treat patients with ESRF in the mid-1970s, the efficacy of once-weekly HD in

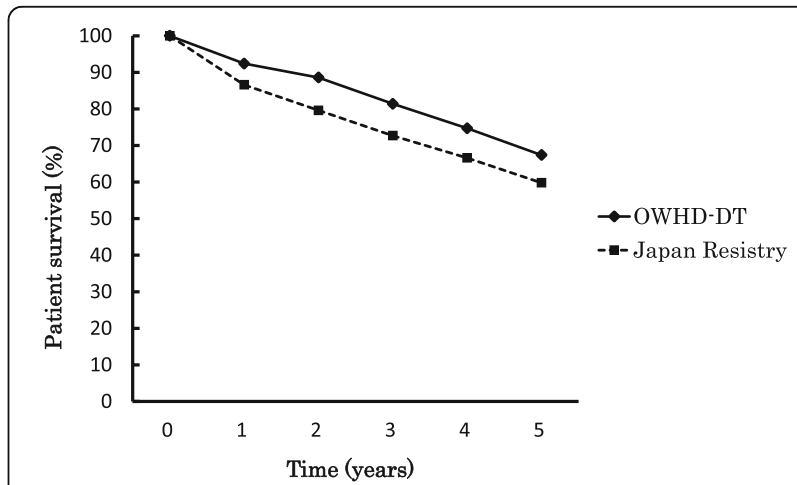

Fig. 5 Comparison of patient survival between patients on once-weekly hemodialysis and diet therapy (OWHD-DT) with patients from the Japan Registry. Log rank $p<0.001$ 
combination with a very low-protein diet supplemented with essential amino acids and ketoacids was reported by Mitch et al. [23], Morelli et al. [24] and Locatelli et al. [25] in the 1980s and 1990s. Those studies reported that infrequent dialysis could have some beneficial points compared to thrice-weekly HD programs begun suddenly during the conservative treatment phase. These benefits include better psychological adaptation to the need for dialysis, better acceptance of conventional HD programs when needed later, and a reduction in costs and organizational problems for both patients and the $\mathrm{Na}$ tional Health Service. More recently, Caria et al. reported a "Combined Diet Dialysis Program" consisting of the application of once-weekly dialysis plus a $0.6 \mathrm{~g} / \mathrm{kg} /$ day low-protein diet. In this study, at the 24-month follow-up, $39.4 \%$ of the patients were still on the program and the survival rate was $94.7 \%$ [26]. Bolasco et al. also recognized the benefits of beginning maintenance dialysis once weekly with incremental transition to more-frequent dialysis therapy [30].

One of the primary purposes of dialysis therapy is to control elevated serum concentrations of uremic solutes, potassium, phosphate, and the excessively accumulated fluids seen in ESRF patients. The National Cooperative Dialysis Study showed the benefit of maintaining lower serum urea nitrogen concentrations in HD patients [1]. The extents of these abnormalities seen in HD patients depend not only on the dialysis dose but also on the rate of accumulation of these substances during the inter-dialytic interval. Regarding the delivered dose of $\mathrm{HD}$, recent guidelines recommend a target $\mathrm{spKt} / \mathrm{V}$ of 1.2-1.4 per HD. The hemodialysis (HEMO) study showed that there was no benefit from more intensive HD (higher per-session Kt/Vurea) when patients underwent thrice-weekly HD [3]. The mean $\mathrm{spKt} / \mathrm{V}$ of the OWHD-DT patients in our study was $1.34 \pm 0.13$, indicating that the dialysis dose for one session of HD is adequate.

The rate of accumulation of fluids and toxic metabolites may largely depend on the ingested quantities from foods and drinks during the inter-dialytic interval. A reduction in dietary protein intake may not only reduce the generation of deleterious nitrogenous metabolic products but could also lead to a concomitant reduction in the intake of both phosphorus and potassium. While solute removal can be augmented by increasing the frequency of HD sessions, rapid accumulation of toxic metabolites and fluids can be prevented by low-protein and low-salt DT. Therefore, the frequency of HD sessions could be reduced by DT. Thus, diet appears to affect the delicate balance of HD frequency in conflicting ways [31].

Good adherence with the diet is essential for safe and successful OWHD-DT. Previously low-protein diets with sufficient energy intake were demonstrated to have no deleterious effect on nutritional status in patients with chronic renal failure [32]. Therefore, reducing protein intake while keeping energy intake stable by increasing carbohydrates and fats can maintain good nutritional status, and prevent the need for higher doses of dialysis. However, because protein-energy wasting is a life-threatening problem in HD patients [33], more investigations is needed to ensure that reducing protein intake is nutritionally safe in the long-term care of dialysis patients. Davies et al. examined both energy and protein intake and reported that despite protein intake being less than that recommended by Kidney Disease Outcomes Quality Initiative guidelines, nutritional status was well maintained in peritoneal dialysis patients whose energy intake was sufficient [34]. In our study, the patients on OWHD-DT maintained the same levels of BMI, serum albumin and serum transferrin throughout of the treatment course. Moreover, the serum albumin levels at 1 and 2 years in the patients on OWHD-DT were actually significantly higher compared with those of the DOPPS patients. Hence, the nutritional status of the patients on OWHD-DT could not be considered to have deteriorated despite low-protein diets. Many protein-reduced products that are made up of carbohydrates and are substantially free of nitrogen compared with regular foods have become commercially available and more palatable $[35,36]$. The study patients actively incorporated these food products into their diets. Therefore, even under restricted protein intake, sufficient energy intake contributes to the maintenance of good nutritional status.

Residual renal function in HD patients has been demonstrated to be a crucial predictor of clinical outcomes, and higher residual urine output has been reported to be significantly associated with a lower risk of death in dialysis patients [37-39]. Furthermore, it has been reported that patients starting maintenance HD therapy two times per week was associated with a slower decline of residual renal function compared with those starting HD three times per week [40, 41]. Given this background, infrequent dialysis has been proposed as a new paradigm for HD initiation [42]. In this present study, the patients on OWHD-DT had significantly higher urine output than those on C-HD at 1 year after starting HD. This fact is consistent with previous reports stating that less-frequent HD was beneficial for preserving residual renal function. However, it is unclear whether OWHD-DT can preserve residual renal function significantly longer than twice-weekly HD. In addition, arteriovenous fistula (AVF) creation in ESRF patients have been shown to be associated with a slowing the decline of the estimated glomerular filtration rate, and it has been suggested that the plausibility of the 'downstream' effects by which the fistula may reach renal vascular beds at both the macro- and microvascular levels [43]. In this study, all patients had 
functional AVF, and it may contribute to preserve their residual renal function.

The prevalence and incidence of end-stage renal disease are increasing, and renal replacement therapy consumes a significant proportion of health care resources in all over the world [44, 45]. This study showed a decrease in medical expense of about $50 \%$ on OWHD-DT than on C-HD. Consistent with our data, Caria et al. also reported that CDDP, namely once-weekly HD combined with a low-protein diet, resulted in an approximate $50 \%$ savings on the cost of medications and dialysis [26]. Hence, OWHD-DT may also be beneficial from an economic point of view.

In our study, the survival rates of the patients on OWHD-DT were better than those of the Japan Registry for the patients who had just started maintenance HD in 2007. Control of body fluid volume must be primarily important issue to achieve adequate maintenance of dialysis patients. To deal with it, $\mathrm{Kt} / \mathrm{V}$ concept is meaningless, and salt restriction should be incorporated [46] In this study, the patients who excellently adhered to low salt intake could survive on OWHD-DT protocol for a long time, showing their interdialytic weight gain around $2.0 \mathrm{~kg}$ over the course of the entire week between treatments. While there is greater medical risk and increased mortality in undernourished dialysis patients, particularly those with hypoalbuminemia, the patients in our study on OWHD-DT had acceptable levels of serum albumin even compared with the DOPPS patients. Furthermore, preserved renal function is suggested to be associated with improved survival among HD patients and the patients on OWHD-DT had greater urine output than those of C-HD patients. Moreover, serial measurements of hemoglobin, urea nitrogen, potassium, phosphate, intact parathyroid hormone, $\beta^{2}$-microglobulin, inter-dialytic body weight gain, blood pressure and cardiothoracic ratio were also maintained in acceptable ranges in the studied patients. Furthermore, the levels of serum CRP in the studied patients were quite low, considering they were hemodialysis patients. All these factors likely contribute to the favorable survival rates of the studied patients. The studied patients all were originally selected patients who had motivation to control their diet, and they were repeatedly received nutritional counselling by a renal dietician once or twice a month. Moreover, physicians gave more careful observations to them than to general population on C-HD. An "enrollment effect" like this may contribute to the better survival of OWHD-DT patients.

One limitation of this OWHD-DT program is that it is not appropriate for every ESRF patient, but only for selected patients who are highly motivated to choose the therapeutic modality and are able to strictly adhere to DT. Moreover, the low-protein diet is safe only in the hands of a multidisciplinary and dedicated staff who thoroughly understand the therapy, including specialized renal dietitians who also have constant oversight. From this point of view, this treatment is likely only to be feasible at a relatively limited number of facilities.

\section{Conclusions}

OWHD-DT may be a safe and cost-effective regimen that provides more HD-free time for selected patients with ESRF. In addition to favorable clinical and economic outcomes, an incremental transition to twice- or thriceweekly HD may create a less stressful transition for the patient to dialysis therapy. However, it must be emphasized that the benefit of OWHD-DT was limited, since only a subset of patients (24\%) could be maintained on this treatment after 2 years.

This treatment cannot be seen as a general maintenance strategy for patients with ESRF, but may represent a favorable option for use with carefully selected, highly motivated patients, with access to continuous support from trained medical staff, especially nutritionists who are experts in prescribing and assisting the maintenance of low-protein, low-salt diets that also provide adequate energy intake.

\section{Abbreviations \\ AVF: Arteriovenous fistula; BMI: Body mass index; C-HD: Conventional thrice- weekly hemodialysis; CRP: C-reactive protein; CTR: Cardiothoracic ratio; DT: Dietary treatment; HD: Hemodialysis; IDW: Interdialytic weight gain; OWHD-DT: Once-weekly hemodialysis combined with dietary treatment; spK/TV: Single pool K/TV}

\section{Acknowledgments}

The authors thank Dr. Hiroshi Mastumoto, Dr. Tomonari Okada, Dr. Hiromi Hidaka, Dr. Maki Yoshino, Dr. Yume Nagaoka, Dr. Toshikazu Wada, Dr. Asako Gondou, and Dr. Yoshitaka Miyaoka, who are previous or present staff of the dialysis unit of Tokyo Medical University, for their medical support.

\section{Funding}

The study was partially funded by grant from Organization for Kidney and Metabolic Disease Treatment. The funding sources were not involved in the study design; the collection, analysis, and interpretation of data; the writing process; or the decision to submit the article for publication.

\section{Availability of data and materials}

The dataset used and/or analyzed during the current study are available from the corresponding author on reasonable request.

\section{Authors' contributions \\ TN, YK made substantial contributions to conception, design and data collection, and drafting and revising the manuscript. MT has been involved in design and data collection. All of the authors have read and approved the final submitted manuscript.}

\section{Ethics approval and consent to participate}

The study is in accordance with Helsinki Declaration. The study protocol has been approved by the ethics committee of Tokyo Medical University (No. 2223, Oct.10, 2012). Written informed consent was obtained from all patients.

Competing interests

The authors declare that they have no competing interests. 


\section{Publisher's Note}

Springer Nature remains neutral with regard to jurisdictional claims in published maps and institutional affiliations.

\section{Author details}

'Department of Clinical Research, Organization for Kidney and Metabolic Disease Treatment, 1-32-1, Okusawa, Setagaya ward, Tokyo 158-0083, Japan. ${ }^{2}$ Department of Human Nutrition, Tokyo Kaseigakuin University, 22, sanbanchou, Chiyoda ward, Tokyo 102-8341, Japan. ${ }^{3}$ Bousei Shinjukuminamiguchi Clinic, 2-9-2 Yoyogi, Shibuya, Tokyo 151-0053, Japan.

\section{Received: 18 June 2017 Accepted: 5 June 2018}

Published online: 28 June 2018

\section{References}

1. Lowrie EG, Laird NM, Parker TF, Sargent JA. Effect of the hemodialysis prescription on patient morbidity - report from the National Cooperative Dialysis Study. N Engl J Med. 1981;305:1176-81.

2. Saran R, Bragg-Gresham JL, Levin NW, Twardowski ZJ, Wizemann V, Saito A, et al. Longer treatment time and slower ultrafiltration in hemodailysis: Associations with reduced mortality in the DOPPS. Kidney Int. 2006;69: 1222-28.

3. Eknoyan G, Beck GJ, Cheung AK, Daugirdas JT, Greene T, Kusek JW, et al. The hemodialysis (HEMO) study group. Effect of dialysis dose and membrane flux in maintenance hemodialysis. N Engl J Med. 2002;347:2010-9.

4. Hanson JA, Hulbert-Shearona TE, Ojob AO, Porta FK, Wolfe RA, Agodoad LYC, et al. Prescription of twice-weekly hemodialysis in the USA. Am J Nephrol. 1999;19:625-33.

5. Kalantar-Zadeh $K$, Unruh M, Zager PG, Kovesdy CP, Bargman JM, Chen J, et al. Twice-weekly and incremental hemodialysis treatment for initiation of kidney replacement therapy. Am J Kidney Dis. 2014;64:181-6.

6. Savla D, Glenn M, Chertow G, Meyer T, Anand S. Can twice weekly hemodialysis expand patient access under resource constraints? Hemodail Int 2017:21:445-52.

7. Tattersall J, Martin-Malo A, Pedrini L, Basci A, Canaud B, Fouque D, et al. EBPG guideline on dialysis strategies. Nephrol Dial Transplant. 2007;22(Suppl 2):ii5-ii21.

8. National Kidney Foundation. KDOQI clinical practice guideline for hemodialysis adequacy: 2015 update. Am J Kidney Dis. 2015;66:884-930.

9. National Kidney Foundation. KDOQI clinical practice guidelines for nutrition in chronic renal failure. Am J Kidney Dis. 2000;35(Suppl 2):S1-141.

10. Fouque D, Vennegoor M, Wee PT, Wanner C, Basci A, Canaud B, et al. EBPG guideline on nutrition. Nephrol Dial Transplant. 2007:22(Suppl 2):ii45-87.

11. Alpers DH, Taylor BE, Bier DM, Klein S. Protein and calories: requirements, intake and assessment. In: Manual of nutritional therapeutics. 6th ed. Philadelphia: Wolters Kluwer; 2015. p. 61-122.

12. Giovannetti S, Maggiore O. A low-nitrogen diet with protein of high biological value for severe chronic uremia. Lancet. 1964;1:1000-4.

13. Kopple JD, Coburn JW. Metabolic studies of low protein diets in uremia: I. Nitrogen and potassium Medicine. 1973;52:583-94.

14. Mandayam S, Mitch WE. Dietary protein restriction benefits patients with chronic kidney disease. Nephrology. 2006;11:53-7.

15. Cianciaruso B, Pota A, Pisani A, Torraca S, Annecchini R, Lombardi P, et al. Metabolic effects of two low protein diets in chronic kidney disease stage 4-5 a randomized controlled trial. Nephrol Dial Transplant. 2008;23:636-44

16. Mitch W, Remuzzi G. Diets for patients with chronic kidney disease, still worth prescribing. J Am Soc Nephrol. 2004;15:234-7.

17. Bellizzi V, Cupisti A, Locatelli F, Bolasco P, Brunori G, Cancarini G, et al. On behalf of the "conservative treatment of CKD" study group of the Italian Society of Nephrology. Low-protein diets for chronic kidney disease patients: the Italian experience. BMC Nephrol. 2016;17:77.

18. Kovesdy CP, Kalantar-Zadeh K. Back to the future: restricted protein intake for conservative management of CKD, triple goals of renoprotection, uremia mitigation, and nutritional health. Int Urol Nephrol. 2016:48:725-9.

19. Walser M, Hill S. Can renal replacement be deferred by a supplemented very low protein diet? J Am Soc Nephrol. 1999;10:110-6.

20. Ideura T, Shimazui M, Higuchi K, Morita H, Yoshimura A. Effect of Nonsuppl -emented low-protein diet on very late stage CRF. Am J Kidney Dis. 2003;41(Suppl 1):s31-4
21. Brunori G, Viola BF, Parrinello G, Biase VD, Como G, Franco V, et al. Efficacy and safety of a very-low-protein diet when postponing dialysis in the elderly: a prospective randomized multicenter controlled study. Am J Kidney Dis. 2007:49:569-80.

22. Dyck PJ, Johnson WJ, Nelson RA, Lambert EH, O'Brien PC. Uremic neuropathy.III. Controlled study of restricted protein and fluid diet and infrequent hemodialysis versus conventional hemodialysis treatment. Mayo Clin Proc. 1975;50:641-9.

23. Mitch WE, Sapir DG. Evaluation of reduced dialysis frequency using nutritional therapy. Kidney Int. 1981;20:122-6.

24. Morelli E, Baldi R, Barsotti G, Ciardella F, Cupisiti A, Dani L, et al. Combined therapy for selected chronic uremic patients: infrequent hemodialysis and nutritional management. Nephron. 1987:47:161-6.

25. Locatelli F, Andrulli S, Prontoriero G, Di F, Bigi MC. Integrated diet and dialysis programme. Nephrol Dial Transplant. 1998:13(Suppl 6):132-8.

26. Caria S, Cupisti A, Sau G, Bolasco P. The incremental treatment of ESRD: a low-protein diet combined with weekly hemodialysis may be beneficial for selected patients. BMC Nephrol. 2014;15:172.

27. Libetta C, Esposito P, Canton AD. Once-weekly hemodialysis: a single-center experience. Am J Kidney Dis. 2015;65:342.

28. Pifer TB, Mccullou KP. Friedrich K, Port KF, Goodkin DA, Maroni BJ, et al. Mortality risk in hemodialysis patients and changes in nutritional indicators: DOPPS. Kidney Int. 2002:62:2238-45.

29. Nakai S, Hanafusa N, Maskane I, Taniguchi M, Hamano T, Shoji T, et al. An overview of regular dialysis treatment in Japan (as of December 2012). Ther Aphr Dial. 2014;18:535-602.

30. Bolasco P, Cupisti A, Locatelli F, Caria S, Kalantar-Zadeh K. Dietary management of incremental transition to dialysis therapy: once-weekly hemodialysis combined with low-protein diet. J Ren Nutr. 2016;26:352-9.

31. Nakao $T$, Matsumoto $H$, Okada $T$, Kanazawa $Y$, Yoshino M, Nagaoka $Y$, et al. Nutritional management of dialysis patients: balancing among nutrient intake, dialysis dose, and nutritional status. A J Kidney Dis 2003; 41 Suppl 1: s133-s136.

32. Bernhard J, Beaufrere B, Lavivile M, Fouque D. Adaptive response to a lowprotein diet in predialysis chronic renal failure patients. J Am Soc Nephrol. 2001;12:1249-54.

33. Kanazawa Y, Nakao T, Murai S, Okada T, Matsumoto H. Diagnosis and prevalence of protein-energy wasting and its association with mortality in Japanese haemodialysis patients. Nephrology. 2017;22:541-7.

34. Davies SJ, Phillips L, Griffiths AM, Naish PF, Russel Gl. Analysis of the effects of increasing delivered dialysis treatment to malnourished peritoneal dialysis patients. Kidney Int. 2000;57:1743-54.

35. D’Alessandro C, Rossi A, Innocenti M, Riccchiuti G, Bozzoli L, Sbragia G, et al Dietary protein restriction for renal patients; don't forget protein-free foods. J Ren Nutr. 2013:23:367-71.

36. KanazawaY MS, Sonoki H, Nakao T. Effects of a novel nutritional formula specially developed for chronic kidney disease patients on protein-restricted diets: a randomized controlled trial. Ren Repl Ther. 2016;2:18.

37. Vilar E, Wellsted D, Chandna SM, Greenwood RN, Farrington K. Residual renal function improves outcome in incremental haemodialysis despite reduced dialysis dose. Nephrol Dial Transplant. 2009;24:2502-10.

38. Shafi T, Jaar BG, Plantinga LC, Fink NE, Sadler JH, Parekh RS, et al. Association of residual urine output with mortality, quality of life, and inflammation in incident hemodialysis patients: the choices for healthy outcomes in caring for end-stage renal disease (CHOICE) study. Am J Kidney Dis. 2010;56:348-58.

39. Lee MJ, Park JT, Park KS, Kwon YE, Oh HJ, Yoo T-H, et al. Prognostic value of residual urine volume, GFR by 24-hour urine collection, and eGFR in patients receiving dialysis. Clin J Am Soc Nephrol. 2017;12:426-34.

40. Lin Y-F, Huang JW, Wu M-S, Chu T-S, Lin S-L, Chen Y-M, et al. Comparison of residual renal function in patients undergoing twice-weekly versus threetimes-weekly haemodialysis. Nephrology. 2009;14:59-64.

41. Zhang M, Wang M, Li H, Yu P, Yuan L, Hao C, et al. Association of initial twice-weekly hemodialysis treatment with preservation of residual kidney function in ESRD patients. Am J Nephrol. 2014;40:140-50

42. Rhee CM, Unruh M, Chen J, Kovesdy CP, Zager P, Kalantar-Zadeh K. Infrequent Dialysis: a new paradigm for hemodialysis initiation. Semin Dial. 2013:26:720-7.

43. Golper TA, Hartle PM, Bian A. Arteriovenous fistula creation may slow estimated glomerular filtration rate trajectory. Nephrol Dial Transplant. 2015;30:2014-9. 
44. US Renal Data System 2016. Annual Data Report Epidemiology of Kidney Disease in the United States, Volume 2: ESRD in the United States chapter11: Medicare expenditure for persons with ESRD. Am J Kidney Dis. 2017;69(Suppl 1):S509-18.

45. Kim SH, Jo MW, Go DS, Ryu DR, Park J. Economic burden of chronic kidney disease in Korea using national sample cohort. J Nephrol. 2017;30:787-93.

46. OkE, Mees EJD. Unpleasant truth about salt restriction. Sem Dial. 2010;23:1-3.

- fast, convenient online submission

- thorough peer review by experienced researchers in your field

- rapid publication on acceptance

- support for research data, including large and complex data types

- gold Open Access which fosters wider collaboration and increased citations

- maximum visibility for your research: over $100 \mathrm{M}$ website views per year 